\title{
ТАЛЛОВОЕ МАСЛО ЗАВОДА КЕХРА, ЕГО СОСТАВ, СВОЙСТВА И ПРИМЕНЕНИЕ В ТЕКСТИЛЬНОЙ ПРОМЫШЛЕННОСТИ
}

\author{
Н. К. ПОЛИКАРПОВ, \\ кандидат технических наук
}

Исследование имело целью изучить состав и свойства таллового масла завода Кехра в Әстонской ССР и найти ему новое применение в технике. Являясь отходом сульфатно-целлюлозного производства, талловое масло, как показали исследования автора этой статьи, может заменить дорогой и дефицитный олеин, применяемый в текстильной промышленности для замасливания шерсти.

Изучение состава таллового масла дало количественное отношение составных частей таллового масла; исследование процесса термического уплотнения таллового масла имело целью проследить те превращения, которые претерпевает талловое масло при нагревании (при изготовлении олифы); изучение процесса этерификации показало, как реагируют жирные и смоляные кислоты таллового масла с различными спиртами; исследование действия диацетонамина имело целью проанализировать возможность разделения жирных и смоляных кислот посредством этого основания; исследование действия крепкой серной кислоты на талловое масло имело целью проследить ее воздействие на составные части таллового масла, а внедренная в текстильную промышленность прочная водоустойчивая эмульсия из таллового и минерального масла дала дешевый заменитель дорогого олеина для замасливания шерсти.

1. Талловое масло получается при сульфатно-целлюлозном производстве в количестве около 20 кг на тонну целлюлозы. Хотя в литературе имеется достаточно сведений о талловых маслах различного происхождения, но пользоваться ими можно лишь для сравнения, так как режим работы завода, а также состав и свойства сырья могут в весьма заметной степени отразиться на составе и свойствах таллового масла (см. табл. 1).

Т а б ли ц а 1

Состав таллового масла

\begin{tabular}{l|c|c|c}
\hline & $\begin{array}{c}\text { Смолян. кислот } \\
\%\end{array}$ & $\begin{array}{c}\text { Жирн. кислот } \\
\%\end{array}$ & $\begin{array}{c}\text { Неомыляемых } \\
\%\end{array}$ \\
\hline \\
Масло Ново-лялинского бум. комби-
\end{tabular}


Детальное исследование состава таллового масла завода Кехра, произведенное методами анализа, разработанными Бобровым $\left({ }^{2}\right)$, Солодким $\left({ }^{9}\right)$, Филлиппсом $\left({ }^{17}\right)$, Диттмаром $\left({ }^{12}\right)$, показало, что оно содержит около $21 \%$ нейтральных веществ, $76 \%$ кислотных веществ и $3 \%$ инкрустов, нерастворимых в воде и эфире. Нейтральные вещества дают после омыления $11-13 \%$ неомыляемых (главным образом стерины), 7,5-8\% жирных и $1,2-1,8 \%$ смоляных кислот. Кислотные вещества состоят в среднем на $30-32 \%$ из жирных и на $44-46 \%$ из смоляных кислот.

Что касается жирных кислот таллового масла, то их качественный со-

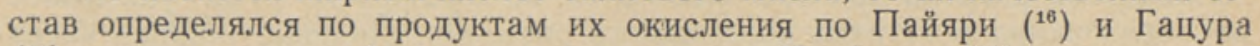
$\left({ }^{13}\right)$, а количественный состав определялся по Кауфману $\left({ }^{15}\right)$ на основании иодных и родановых чисел; содержание ненасыщенных кислот определялось по Бертраму $\left({ }^{10}\right)$. Для получения исчерпывающих данных о составе жирных кислот их этиловые эфиры подвергались молекулярной разгонке в вакууме $10^{-4}$ мм.

В полученных отдельных фракциях определялись числа омыления, нодные и родановые числа, содержание насыщенных кислот и другие константы. При таком высоком вакууме в первых погонах (около $100^{\circ}$ ) преобладают эфиры олеиновой кислоты, затем, с повышением температуры, начинают преобладать эфиры линолевой кислоты, а начиная с $150^{\circ}$ появляются эфиры стеариновой кислоты. Как молекулярная разгонка эфиров жирных кислот, так и непосредственный анализ жирных кислот дают в среднем $54,1 \%$ линолевой кислоты, $37,8 \%$ олеиновой и $8,1 \%$ стеариновой кислоты.

Смоляные кислоты таллового масла содержат 88-92\% неокисленных смоляных кислот, растворимых в бензине, и 8-12\% окисленных смоляных кислот, нерастворимых в бензине.

Неомыляемые состоят главным образом из стеринов с темп. плавл. от 131 до $142^{\circ}$.

2. Процесс термического уплотнения таллового масла состоял в его нагревании на $250-350^{\circ}$ с улавливанием жидких и газообразных продуктов отгона, которые также как и неперегоняемый остаток подвергались исследованию (см. табл. 2).

Т а блиц а 2

Изменение констант при термическом уплотнении таллового масла

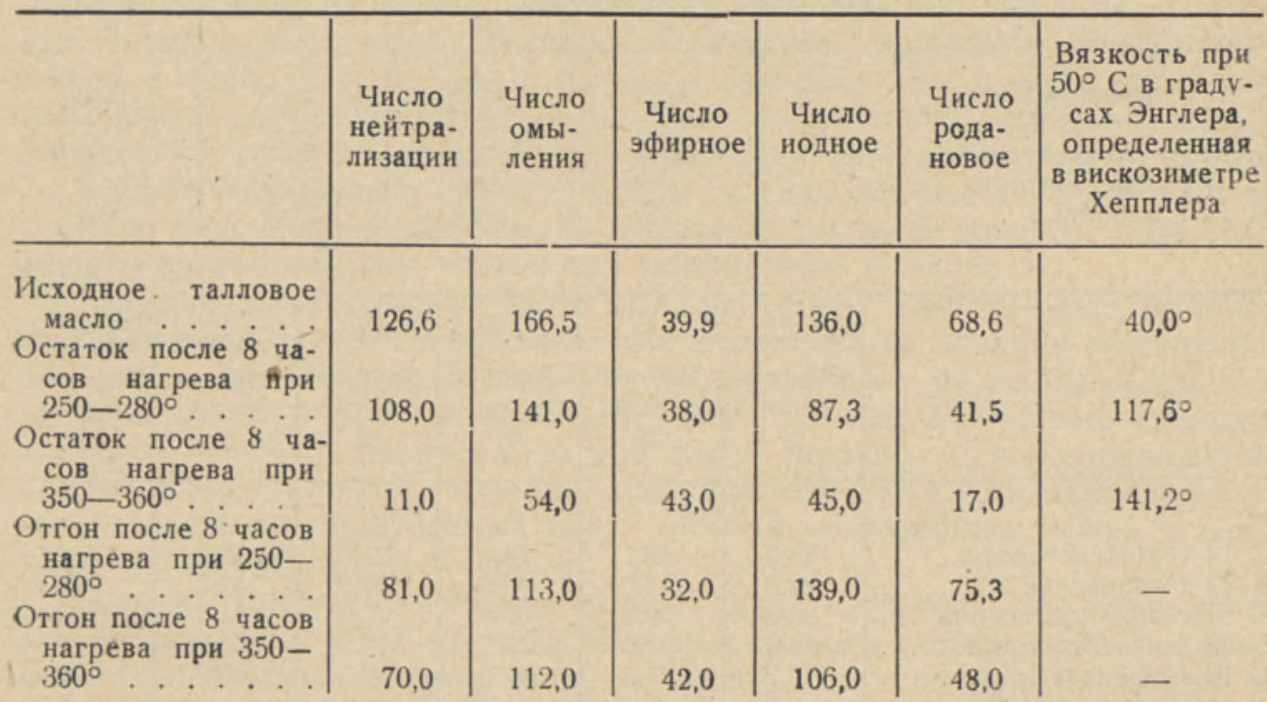


При нагреве таллового масла в течение 8 часов при 350 - $360^{\circ}$ отгоняется $21 \%$ веществ, в том числе - $6,4 \% \mathrm{CO}_{2}, 5,6 \% \mathrm{H}_{2} \mathrm{O}, 4,6 \%$ неомыляемых, $4,2 \%$ жирных и $0,2 \%$ смоляных кислот. Остаток составляет $79 \%$ и состоит на $34,0 \%$ из продуктов полимеризации, $7,5 \%$ стеринов, $14,0 \%$ жирных и 23,5\% смоляных кислот.

В ы в о ды. Сильное падение числа омыления у остатка при нагреве в течение 8 часов при $350-360^{\circ}$ обуславливается конденсацией частиц с почти удвоенным молекулярным весом; сильное возрастание вязкости за то же время нагрева при $350-360^{\circ}$ с $40^{\circ}$ по Энглеру до $141,2^{\circ}$ указывает на образование в остатке коллоидного раствора. Падение иодных чисел при тех же условиях нагрева объясняется взаимным насышением двойных связей в результате соединений углеродных атомов между собою, приводящим к полимеризации молекул; падение числа нейтрализации у неперегоняемого остатка указывает, что остаток обогатился' продуктами полимеризации и неомыляемыми. Выделение $\mathrm{CO}_{2}$ и $\mathrm{H}_{2} \mathrm{O}$ указывает на наличие процесса дегидратации и декарбоксилизации. Переход в отгон органических веществ происходит главным образом при $280-360^{\circ}$, причем доля смоляных кислот, перешедших в отгон, очень незначительна. Отгон состоит на $51,0 \%$ из неомыляемых, $47,4 \%$ жирных и $1,6 \%$ смоляных кислот.

3. Процесс этерификации таллового масла исследовался с целью установления, при каких температурах и за какой период времени происходит образование эфиров и какие условия благоприятствуют образованию эфиров жирных кислот в отличие от эфиров смоляных кислот. В качестве этерификаторов брались: этиленгликоль, глицерин, триэтаноламин, пентаэритрит и маннит в количестве на 1 моль таллового масла 1,3 моля спирта, деленное на число гидроксилов спирта. Талловое масло бралось одного и того же состава с содержанием $21 \%$ нейтральных веществ. Нагревание с различными спиртами происходило в течение 6 часов в токе $\mathrm{CO}_{2}$ пря постоянном перемешивании. Прощент вновь образовавшихся эфиров из 100 г таллового масла в разных интервалах температуры приведен в табл. 3.

T а бли ц а 3

Количество вновь образовавшихся эфиров при нагреве таллового масла

\begin{tabular}{|c|c|c|c|c|}
\hline & $\begin{array}{c}\text { При } 110- \\
130^{\circ} \\
\%\end{array}$ & $\begin{array}{c}\text { При } 130- \\
160^{\circ} \\
\%\end{array}$ & $\begin{array}{c}\text { При } 160- \\
200^{\circ} \\
\%\end{array}$ & $\begin{array}{c}\text { При } 200- \\
2 \varepsilon 0^{\circ} \\
\%\end{array}$ \\
\hline 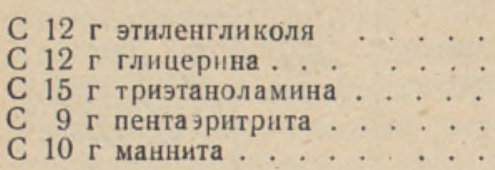 & $\begin{array}{r}15,0 \\
7,3 \\
27,5 \\
2,2 \\
4,0\end{array}$ & $\begin{array}{l}33,5 \\
15,3 \\
46,6 \\
14,0 \\
12,6\end{array}$ & $\begin{array}{l}49,0 \\
61.5 \\
79.0 \\
33,4 \\
26,5\end{array}$ & $\begin{array}{l}79,0 \\
61,5 \\
79,0 \\
64,0 \\
59,8\end{array}$ \\
\hline
\end{tabular}

Т а блиц а 4

\begin{tabular}{|c|c|c|c|c|c|c|}
\hline & \multicolumn{2}{|c|}{ При $110-130^{\circ}$} & \multicolumn{2}{|c|}{ При $130-160^{\circ}$} & \multicolumn{2}{|c|}{ Гри $160-20\left(1^{\circ}\right.$} \\
\hline & $\begin{array}{c}\text { Эфнры } \\
\text { жирн. } \\
\%\end{array}$ & $\begin{array}{c}\text { Эфиры } \\
\text { смолян. } \\
\%\end{array}$ & $\begin{array}{c}\text { Эфиры } \\
\text { жирн. } \\
\%\end{array}$ & $\begin{array}{c}\text { Эфиры } \\
\text { смолян. } \\
\%\end{array}$ & $\begin{array}{c}\text { Эфиры } \\
\text { жирн. } \\
\%\end{array}$ & $\begin{array}{c}\text { Эфиры } \\
\text { смолян. } \\
\%\end{array}$ \\
\hline 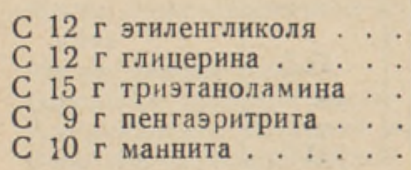 & $\begin{array}{l}83,9 \\
87,0 \\
90,8 \\
80,0 \\
72,2\end{array}$ & $\begin{array}{r}16,1 \\
13,0 \\
9,2 \\
2,1,0 \\
27,8\end{array}$ & $\begin{array}{l}78,4 \\
63,0 \\
60,0 \\
78,3 \\
57,5\end{array}$ & $\begin{array}{l}21,6 \\
37,0 \\
40,0 \\
21,7 \\
42,5\end{array}$ & $\begin{array}{l}53,8 \\
43,7 \\
45,4 \\
61,9 \\
40,0\end{array}$ & $\begin{array}{l}46,2 \\
56,3 \\
54,6 \\
38,1 \\
60,0\end{array}$ \\
\hline
\end{tabular}


Наибольшей активностью обладает триэтаноламин; наименьшей маннит, что обуславливается наличием в нем вторичных гидроксилов $\left(^{1}\right)$. В зависимости от температур нагрева соотношение между эфирами жирных и смоляных кислот при нагреве 100 г таллового масла в течение 6 часов в токе $\mathrm{CO}_{2}$ изменяется согласно табл. 4 .

Низкие температуры содействуют образованию эфиров жирных кислот, по мере повышения температуры возрастает число эфиров смоляных кислот. Ведя процесс этерификации при $240-260^{\circ}$, имеем быстро идущую реакцию, сопровождающуюся сильным падением чисел нейтрализации исходных смесей (см. табл. 5).

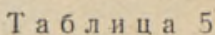

Числа нейтрализации продуктов этерификации 100 г таллового масла в токе $\mathrm{CO}_{2}$ при $240-260^{\circ}$

\begin{tabular}{|c|c|c|c|c|}
\hline & Начальное & $\begin{array}{c}\text { В течение } \\
2 \text { часов }\end{array}$ & $\begin{array}{c}\text { В течение } \\
4 \text { часов }\end{array}$ & $\begin{array}{c}\text { В течение } \\
6 \text { часов }\end{array}$ \\
\hline $\begin{array}{l}\text { C } 12 \text { г глицерина. . . . } \\
\text { C } 10 \text { г маннита... } \\
\text { C } 15 \text { г триэтаноламина . }\end{array}$ & $\begin{array}{l}130 \\
120 \\
103\end{array}$ & $\begin{array}{l}36,2 \\
80,0 \\
26,5\end{array}$ & $\begin{array}{r}17,0 \\
19,0 \\
6,0\end{array}$ & $\begin{array}{r}10,0 \\
10,0 \\
0,0\end{array}$ \\
\hline
\end{tabular}

При 6-часовом нагреве при $240-260^{\circ}$ продукты этерификации получаются в виде густых, вязких, липких масс; присутствие в них эфиров стеариновой кислоты способствует образованию медленно сохнущих пленок.

4. Основываясь на способности диацентонамина $-\left(\mathrm{CH}_{3}\right)_{2}-\mathrm{C}\left(\mathrm{NH}_{2}\right)-$ $\mathrm{CH}_{2}-\mathrm{CO}-\mathrm{CH}_{3}$, как основания, давать соли со смоляными кислотами (") , была исследована возможность разделения жирных и смоляных кислот с целью дать для бумажной промышленности заменитель канифоли, а жировой промышленности - чистые жирные кислоты. Однако целый ряд опытов показал, что осадок, получаемый при действии сухого аммиака на раствор таллового масла в ацетоне, не представляет чистую соль диацетонаминового основания со смоляными кислотами, но что этот осадок содержит около $85 \%$ соли диацетонамина с неокисленными смоляными кислотами и $15 \%$ соли диацетонамина с жирными кислотами. Таким образом, если по этому способу нельзя полностью отделить смоляные кислоты от жирных, то все же удается разделить талловое масло на две части - около $30 \%$ осадка, богатого смоляными кислотами (неокисленными) и около $70 \%$ раствора, богатого жирными кислотами и содержащего, кроме того, нейтральные вешества и окисленные смоляные кислоты. Окисленные смоляные кислоты в реакцию с диацетонамином не вступают.

5. Действие крепкой серной кислоты на талловое масло исследовалось с целью выяснения ее влияния на жирные и смоляные кислоты и на возможность изготовления заменителя ализаринового масла.

Крепкая серная кислота уд. в. 1,84 при $12-16^{\circ}$ прибавлялась по каплям при непрерывном перемешивании к талловому маслу в количестве $15 \%$ веса масла. Ввиду большой вязкости талловое масло было предварительно растворено в петролейном эфире. После 12-часового стояния талловое масло разделилось на два слоя: верхний - легкоподвижный (около 60\%) и нижний - густой, вязкий (около $40 \%$ ). Составы верхнего и нижнего слоев, получаемых после отгонки петролейного эфира и нейтрализации, приведены в табл. 6.

При указанном соотношении между серной кислотой и талловым маслом серная кислота действует на смоляные кислоты главным образом окислительно, жирные кислоты лишь в нижнем слое частично переходят в 


\begin{tabular}{|c|c|c|}
\hline & $\underset{\%}{\text { Верхний слой }}$ & $\underset{\%}{\text { Ннжний слой }}$ \\
\hline $\begin{array}{l}\text { Неомыляемых } \\
\text { Жнрных кислот } \\
\text { Жирных оксикислот } \\
\text { Неокислен. смоляных кислот } \\
\text { Окислен. смоляных кислот } \\
\text { Нерастворимых примесей }\end{array}$ & $\begin{array}{r}3,6 \\
22,7 \\
\overline{25,0} \\
0,3 \\
1,7\end{array}$ & $\begin{array}{r}7,3 \\
14,2 \\
0,7 \\
16,0 \\
6,9 \\
1,6\end{array}$ \\
\hline & 53,3 & 46,7 \\
\hline
\end{tabular}

оксикислоты. Увеличивая количество серной кислоты до $25 \%$, получаем в нижнем слое до $15 \%$ окисленных смоляных кислот и до $7 \%$ жирных оксикислот. Верхний слой, будучи нейтрализован, может служить заменителем ализаринового масла, давая с водой прочную, устойчивую эмульсию.

6. До последнего времени талловое масло применялось главным образом для изготовления олифы (для внутренних покрытий) и в мыловарении. Автору этой работы удалось разработать и ввести в производство применение таллового масла как заменителя олеина при замасливании шерсти. Применявшийся для этой цели в текстильной промышленности олеин является дорогим и остродефицитным материалом и потому не раз делались попытки найти дешевый заменитель олеина.

Минеральное масло, частично заменяя олеин, не давало прочной и устойчивой эмульсии $\left({ }^{6}\right)$; разработанные в 1937 г. «неволи», состоящие на $75 \%$ из минерального масла, $19 \%$ олеина и $6 \%$ триэтаноламина, давали хорошие результаты, однако недостаток триэтаноламина $\left({ }^{3}\right)$ и относительно высокий процент олеина препятствовали широкому распространению этих «неволей». Первоначальные работы автора этой статьи велись в направлении частичной замены олеина канифолью; оказалось, что такая смесь из олеина и канифоли дает с минеральным маслом в высшей степени устойчивую эмульсию. Оставалось, следовательно, найти такое вещество, которое совмещало бы в себе свойства олеина и канифоли, было бы дешево, без запаха и легко удалялось бы из шерсти при промывке. Такое вещество и было найдено в талловом масле. Автором был разработан и внедрен в производство на текстильной фабрике имени 1 декабря в г. Синди ЭССР следующий способ изготовления прочной водоустойчивой эмульсии для замасливания шерсти: 3000 г таллового масла подогреваются и при перемешивании добавляется 1100 г минерального масла. Эта смесь омыляется постепенно раствором едкого натра (1100 г воды на 800 г едкого натра уд. в. 1,33). Когда получится равномерная смесь, добавляют еще постепенно 5000 г минерального масла. Полученная консистентная масса разводится водой так, что на одну часть консистентной массы берется от 6 до 10 частей воды в зависимости от того, какую степень жирности хотят придать шерсти. Получается эмульсия молочного цвета, не выделяющая капель масла при стоянии, без запаха и легко вымывающаяся из шерсти. Эмульсия представляет систему двух не смешивающихся между собою жидкостей - минерального масла, находящегося в состоянии тончайшего распыления, и воды; устойчивость системы обуславливается присутствием эмульгатора - таллового масла в виде натриевых солей жирных и смоляных кислот и неомыляемых стеринов. 
При цене олеина 8 руб. за кг и таллового масла 2 руб. за кг (по ценам 1949 г.) эмульсия из таллового масла обходится в 4 раза дешевле олеиновой и освобождает местные фабрики от привоза дефицитного олеина. За 1949 г. текстильная фабрика имени 1 декабря в г. Синди ЭССР употребила 5000 кг таллового масла для замасливания шерсти.

\section{Выводы}

1. Произведен детальный анализ жирных кислот таллового масла. Путем молекулярной разгонки этиловых эфиров жирных кислот, определения иодных и родановых чисел отдельных фракций и исследования продуктов окисления установлен качественный и количественный состав жирных кислот.

2. Смоляные кислоты таллового масла подразделены на неокисленные и окисленные.

3. Исследование процесса термического уплотнения таллового масла показало, что при нагреве до $280-360^{\circ}$ происходит изменение констант таллового масла, обуславливаемое конденсацией и полимеризацией молекул. В отгон переходит очень малое количество смоляных кислот.

4. Исследование процесса этерификации показало, что при прочих равных условиях триэтаноламин обладает наибольшей активностью. В пределах температуры $110-130^{\circ}$ этерифицируются главным образом жирные кислоты, смоляные же-слабо; с повышением температуры этерификация смоляных кислот идет энергичнее.

5. Исследование действия диацетонамина на талловое масло показало, что это основание может разделить талловое масло на две части - на часть, богатую смоляными кислотами, и другую часть - богатую жирными кислотами.

6. Исследование действия крепкой серной кислотой на талловое масло показало, что она действует окислительно главным образом на смоляные кислоты и лишь в слабой степени на жирные кислоты, образуя малое количество жирных оксикислот.

7. Талловое масло в смеси с минеральным маслом дает прочную водоустойчивую эмульсию, заменяющую олеиновую эмульсию при замасливании шерсти. Будучи в 4 раза дешевле олеина, талловое масло нашло для этой цели широкое применение в текстильной промышленности Әстонской CCP.

Ннститут промышленных проблем Академии Наук Эстонской ССР

\section{ЛИТЕРАТУРА}

1. А. А. Бл агон ра вов а и А. Я. Д р и нбе рг, О продуктах этерификации жирных кислот с одной двойной связью и их высыхание, «Журнал прикладной хнмни», т. 12,1938 , стр. 1642.

2. П. А. Б о бр ов, О составе древесной смолы, «Журнал прикладной химин», т. 2, 1929 , стр. 403.

3. В. В. Голосов, Эмульсии с триэтаноламином и этиленгликолем, «Текстильная промышленность», № 9-10, 1946.

4. А. Я. Д р и н 6 е р г, Искусственные олифы, Л., 1947, стр. 110.

5. Институт жировой промышленности, Маслобойно-жировое дело, № 12, 1934.

6. А. М. М о то р и н, Журн. «Шерстяное дело», № 4, 1931.

7. Н. К. П ол и к а р П о в, Талловое масло ЭССР, его состав, свойства и техническое применение, Автореферат, Таллин, 1950.

8. Е. В. Р ог н н к а я, О химическом составе древесной смолы, «Журнал прнкладной хнмии», т. 7,1947 , стр. 564. 
9. Ф. Т. С ол од к и й, О составе сульфатного мыла и приемах его использования, Сборник лесохимических работ Лесотехнической академии им. С. М. Қирова, № 16, 1938.

10. S. B e rt r a m, Zeitschr. deutsch. Ol- und Fettindustrie, Nr. 45, 1925, S. 733.

11. R. B le ng s l y, Talloil, «Paper Trade Journal», No 9, 1940.

12. K. D itt ma r, Ober Tallöl, «Zeitschr. f. angew. Chemie», Nr. 39, 1926, S. 263.

13. H. H a z u r a, Monatsheite d. Chemie, 1887, S. 147.

14. E. J a c o b s o n, «Svensk Pappers Tidning», No 18, 1939, 473.

15. H. K a u f m a n n, Studien auf dem Fettgebiet, 1925, S. 150-157.

16. K. P a j a ri, Untersuchungen über Kieferrinde, Helsinki, 1943.

17. J. Philipps, The Resins of Jack-Pine, «Pulp and Paper Magazine of Canada», No $2,1931$. 